\title{
2586. Influence of curing time on impact energy absorption characteristics of artificially cemented sand
}

\author{
Pu Yuan', Ying $\mathrm{Xu}^{2}$ \\ ${ }^{1,2}$ School of Civil Engineering and Architecture, Anhui University of Science and Technology, \\ Huainan 232001, P. R. China \\ ${ }^{1}$ Engineering Research Center of Underground Mine Construction, Ministry of Education, \\ Anhui University of Science and Technology, Huainan 232001, P. R. China \\ ${ }^{1}$ Corresponding author

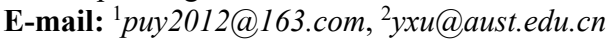

Received 11 November 2016; received in revised form 2 April 2017; accepted 22 April 2017 DOI https://doi.org/10.21595/jve.2017.18004

Check for updates

\begin{abstract}
To investigate the influence of curing time on impact energy absorption characteristics of artificially cemented sand in geomechanical model experiments, aluminium split Hopkinson pressure bar apparatus with bar diameter of $37 \mathrm{~mm}$ has been developed to conduct impact uniaxial compression tests under various striker velocities. The curing times of artificially cemented sand are 7 days, 14 days, and 21 days, respectively. Then test results have been analyzed from the energy point of view. Test results show that only a small amount of energy goes through the specimen and passes into transmitted bar in impact uniaxial compression tests, while most of incident energy is reflected back to incident bar for relatively low wave impedance of artificially cemented sand. With striker velocity increasing, there is an obviously positive linear relation between specific energy absorption (SEA) of artificially cemented sand specimens and squared striker velocity. As the bonding, mechanical behaviors between sand particles are gradually strengthened with curing time growing, the impact energy absorption characteristics of artificially cemented sand increases with curing time growing under certain striker velocity condition. And the increasing rate from 7 days to 14 days is slower, while it is faster from 14 days to 21 days. With respect to the SEA of artificially cemented sand cured 7 days, the impact energy absorption increase factor (IEAIF) of artificially cemented sands cured 14 days and 21 days are 1.19 and 1.48 , respectively.
\end{abstract}

Keywords: artificially cemented sand, curing time, split Hopkinson pressure bar (SHPB), specific energy absorption (SEA), impact energy absorption characteristics.

\section{Introduction}

Nowadays, three dimensional geomechanical model experiment becomes a significant way to carry out researches in underground engineering $[1,2]$. Therefore, how to reduce the period and accelerate the process becomes an important issue in three dimensional geomechanical model experiment. Granular cementitious materials are applied as similar materials in geomechanical model experiment, such as artificially cemented sand [3,4] and iron-barite-sand mixed material [5]. For granular cementitious materials, curing time has a great influence on their mechanical properties and deformation characteristics. The influence of curing time on static uniaxial compressive strength of artificially cemented sand has been investigated, then a unique relationship has been achieved linking the uniaxial compressive strength with the curing time [6]. With the help of aluminium split Hopkinson pressure bar (SHPB) apparatus, both the static and dynamic uniaxial compressive strengths of artificially cemented sand have been studied under 3 kinds of curing times [7].

The deformation and failure of rock is a process of energy dissipation [8]. In underground engineering, rock mass excavation is always accompanied with the input, accumulation, dissipation and release of energy [9]. Studying the energy evolution during rock deformation is helpful for promoting the understanding and research of problems in deep rock mechanics. Based on the results of in-situ stress measurement and rock mechanical test, the distribution and variation law of rock mass energy accumulation caused by deep mining are revealed by FLAC ${ }^{3 \mathrm{D}}$ simulation, 
then location and intensity of rock burst during future mining process in Sanshandao gold mine are predicted with the help of seismology method [10]. Numerical simulation indicates that the fracture is likely to initially occur near the rock surface and then propagate towards the internal zone of rock mass, and the elastic energy releasing rate gradually increases with fracture propagating [11]. After studying strain field and energy field of circular tunnel, discontinuity of the radial strain and the concentration of elastic deformation energy have been found at the ultimate balance boundary [12].

When carrying out underground engineering research by three-dimensional geomechanical model experiment, dynamic deformation and failure of deep rock mass in model experiment can be analyzed from the energy point of view. In the first place, the energy absorption characteristics of similar materials should be investigated. To explore and analyze the influence of curing time on impact energy absorption characteristics of artificially cemented sand, impact uniaxial compression tests under various striker velocities are carried out for artificially cemented sand cured 7 days, 14 days, and 21 days, with the help of aluminium split Hopkinson pressure bar (SHPB) apparatus. Then test results are analyzed from the energy point of view.

\section{Preparation of artificially cemented sand specimens and modified SHPB apparatus}

\subsection{Preparation of artificially cemented sand specimens}

In three-dimensional geomechanical model experiment, the proportion and type of similar materials are determined by Froude's similarity law and basic physical mechanical properties of deep rock. Generally, similar materials give first priority to raw materials with abundant source and low price. Artificially cemented sand is such a similar material which is made by sand, Portland cement, gypsum and water [13]. The mass ratio of sand, composite Portland cement (P.C 32.5), gypsum and water is 1:0.13:0.05:0.10. In order to improve the precision and accuracy of the experiment, fine sand with diameter less than $1.18 \mathrm{~mm}$ is adopted. After mixing them according to designed proportion, the mixture is put into mould with a certain pressure. The mould are removed after 24 hours and artificially cemented sand specimens are cured with a thin plastic film cover.

Former research indicates that when length-diameter ratio of specimen is about 0.5 , both the inertial effect and the frictional effect in impact uniaxial compression tests will reach its minimum value [14]. In impact uniaxial compression tests, artificially cemented sand specimens are manufactured into disc specimens. Its diameter is $37 \mathrm{~mm}$ and its length is $19 \mathrm{~mm}$. Artificially cemented sand specimens in disc shape are shown in Fig. 1. The end faces of artificially cemented sand specimens should be flat. The deviation of two parallel end faces should be controlled within $0.05 \mathrm{~mm}$ and the deviation of end face flatness should be controlled within $0.02 \mathrm{~mm}$.

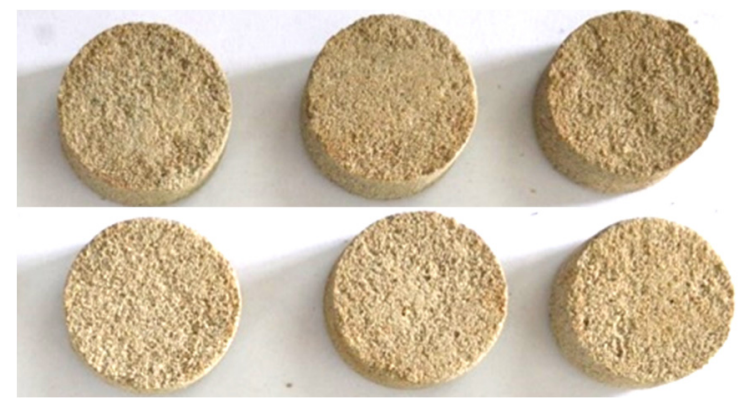

Fig. 1. Artificially cemented sand specimens

During three-dimensional geomechanical model experiment, relatively long loading stage should be proceeded when the strength of artificially cemented sand is in an essentially constant period. Considering the strength growth curve of composite Portland cement and reasonable cycle 
time of geomechanical model experiments, three curing times, 7 days, 14 days, and 21 days, are chosen. After curing 7 days, 14 days, and 21 days, the static uniaxial compressive strength of artificially cemented sand specimens are $3.65 \mathrm{MPa}, 4.79 \mathrm{MPa}$, and 5.28 MPa, respectively. And their elastic wave velocities are $2117 \mathrm{~m} / \mathrm{s}, 2355 \mathrm{~m} / \mathrm{s}$, and $2407 \mathrm{~m} / \mathrm{s}$, respectively.

\subsection{Modified SHPB apparatus}

Impact uniaxial compression tests for artificially cemented sand have been carried out in impact dynamics laboratory of Anhui University of Science and Technology. As shown in Fig. 2, aluminium split Hopkinson pressure bar apparatus is adopted. The diameters of all pressure bars are $37 \mathrm{~mm}$. The length of striker is $800 \mathrm{~mm}$. The lengths of incident bar and transmitted bar are both $2000 \mathrm{~mm}$.

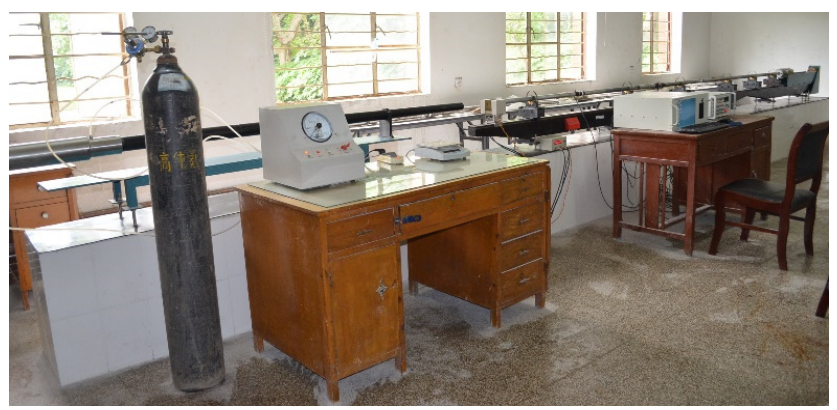

Fig. 2. Aluminium split Hopkinson pressure bar apparatus

In a typical impact uniaxial compression test, incident stress wave is generated by impact of striker on incident bar. Generally, the striker is launched by a sudden release of compressed air in gas gun. Seven striker velocities have been carried out by changing air pressure. To facilitate stress equilibrium, vaseline is used to extend the rising time of the incident wave by smearing them on the impact face of incident bar [15].

The strain waves associated with one-dimensional stress waves are measured by strain gauges mounted symmetrically on the pressure bar surface across the diameter. Then strain gauges are connected into a Wheatstone bridge. Dynamic strain test system composed of strain gauges, super dynamic strain amplifier and dynamic testing analyzer are used to collect and record incident strain wave, reflected strain wave, and transmitted strain wave.

Ordinary foil type resistance strain gauges have been used for incident bar to capture incident strain wave and reflected strain wave. For relatively low wave impedance of artificially cemented sand, semiconductor strain gauges have been adopted for transmitted bar to capture extremely weak transmitted strain wave, and the sensitivity coefficient of semiconductor strain gauges is 110 which is about 50 times bigger than that of ordinary foil type resistance strain gauges [16, 17].

As the semiconductor strain gauges are easily influenced by temperature, four semiconductor strain gauges are connected into a complete Wheatstone bridge. Two working strain gauges mounted symmetrically on the transmitted bar are connected to the opposite legs of the complete Wheatstone bridge. To eliminate the influence of temperature, two temperature compensation strain gauges are mounted on a aluminium plate in same material with transmitted bar subjecting to no load.

With the help of dynamic strain test system, the actual measured incident strain wave, reflected strain wave, and transmitted strain wave are shown in Fig. 3. 


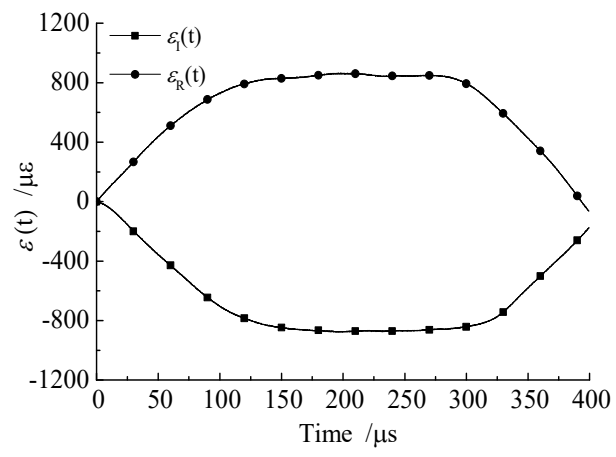

a) Incident strain wave and reflected strain wave



b) Transmitted strain wave

Fig. 3. Actual measured incident strain wave, reflected strain wave, and transmitted strain wave

\section{Impact energy absorption characteristics of artificially cemented sand}

\subsection{Energy calculation in impact uniaxial compression tests}

In impact uniaxial compression tests, there are mainly four kinds of energies involved, which are incident energy $W_{I}$, reflected energy $W_{R}$, transmitted energy $W_{T}$ and absorbed energy $W_{S}$ of artificially cemented sand specimen [18-20]. Incident energy $W_{I}$, reflected energy $W_{R}$, and transmitted energy $W_{T}$ can be calculated by following equations:

$W_{I}=E A C \int \varepsilon_{I}^{2}(t) d t$,
$W_{R}=E A C \int \varepsilon_{R}^{2}(t) d t$,
$W_{T}=E A C \int \varepsilon_{T}^{2}(t) d t$,

where $\varepsilon_{I}(t), \varepsilon_{R}(t)$, and $\varepsilon_{T}(t)$ stand for incident strain wave, reflected strain wave, and transmitted strain wave, respectively. $E, A$, and $C$ are elastic modulus, cross-sectional area, and elastic wave velocity of aluminium pressure bar, respectively.

In impact uniaxial compression tests, frictional contact energy loss can be negligible. According to the law of energy conservation, absorbed energy $W_{S}$ of artificially cemented sand specimen can be calculated by following equation:

$W_{S}=W_{I}-W_{R}-W_{T}$.

Based on the stress uniform assumption, Eq. (4) can be simplified as below:

$W_{S}=2 E A C \int \varepsilon_{R}(t) \varepsilon_{T}(t) d t$

Specific energy absorption (SEA) is a significant indicator for impact energy absorption characteristics. Specific energy absorption (SEA) is defined as absorbed energy $W_{S}$ divided by its volume during impact uniaxial compression tests, which is the area below the dynamic stress-strain curve. It reflects the energy absorbed by material per unit volume [21], and can be calculated by following equation:

$S E A=\frac{W_{S}}{A_{S} l_{S}}=\frac{2 E A C}{A_{S} l_{S}} \int \varepsilon_{R}(t) \varepsilon_{T}(t) d t$, 
where $A_{S}$ and $l_{S}$ are cross-sectional area and length of artificially cemented sand specimen, respectively.

\subsection{Impact energy absorption analyses of artificially cemented sand}

According to mentioned calculation equations, time-history curves of incident energy $W_{I}$, reflected energy $W_{R}$, transmitted energy $W_{T}$, and absorbed energy $W_{S}$ of artificially cemented sand specimen can be seen in Fig. 4.

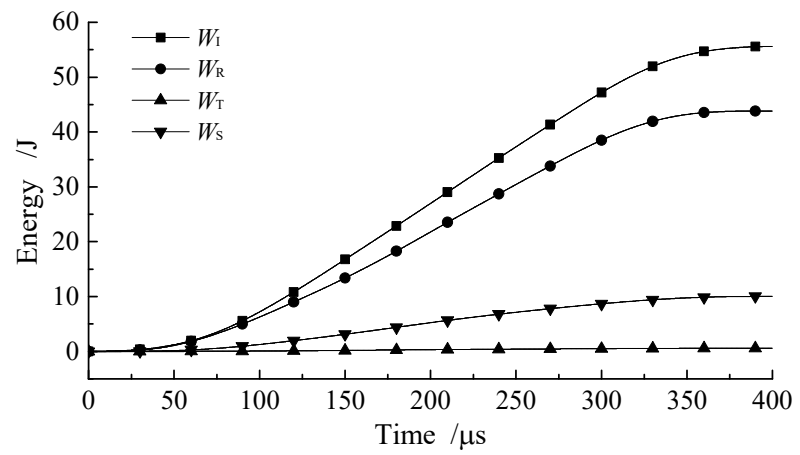

Fig. 4. Curve of energy versus time for artificially cemented sand specimen

Seen from Fig. 4, both incident energy $W_{I}$ and reflected energy $W_{R}$ increase with loading time $(t)$ increasing. For relatively low wave impedance of artificially cemented sand, most of incident wave is reflected, therefore transmitted energy $W_{T}$ is relatively small. Absorbed energy $W_{S}$ of artificially cemented sand specimen also increases with loading time increasing.

Artificially cemented sand absorbed energy is mainly used for damage evolution, crack propagation, and fracture. With the striker velocity increasing, some micro-cracks which will not propagate under low strain rate develop into macro-cracks and connect with each other under high strain rates. This will consume more energy. Moreover, artificially cemented sand shows an obvious strain rate effect during impact uniaxial compression tests. Both dynamic uniaxial compressive strength and ultimate strain of artificially cemented sand increase with strain rate increasing [13]. As the specific energy absorption (SEA) is the area below the dynamic stress-strain curve, specific energy absorption (SEA) also increases with strain rate or striker velocity increasing.

The relation between average specific energy absorption (SEA) and striker velocity $(v)$ for artificially cemented sand cured 7 days, 14 days, and 21 days are shown in Fig. 5.

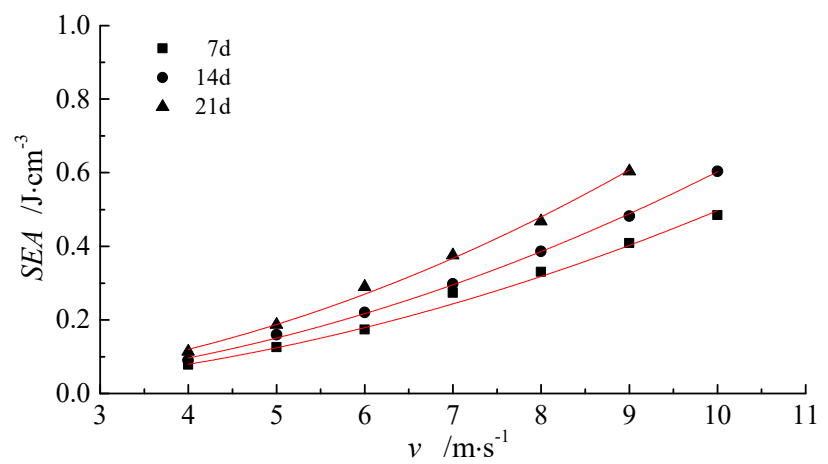

Fig. 5. Curve of specific energy absorption versus striker velocity for artificially cemented sand

Seen from Fig. 5, specific energy absorption (SEA) of artificially cemented sand cured 7 days, 
14 days, and 21 days increase in an approximate power relation with striker velocity. Through fitting analyses, specific energy absorption and striker velocity meets the following relation:

$S E A=a v^{2}$,

where $a$ is a pending fitting coefficient.

Fitting results indicate that a positive linear relation exists between specific energy absorption and squared striker velocity. Pending fitting coefficient $a$ and fitting relation coefficient $R^{2}$ for artificially cemented sand cured 7 days, 14 days, and 21 days are shown in Table 1. Coefficient $a$ increases with curing time increasing.

Table 1. Fitting parameter for artificially cemented sand absorbed energy and striker velocity

\begin{tabular}{|c|c|c|}
\hline Curing time & $a$ & $R^{2}$ \\
\hline $7 \mathrm{~d}$ & 0.00497 & 0.997 \\
\hline $14 \mathrm{~d}$ & 0.00600 & 0.999 \\
\hline $21 \mathrm{~d}$ & 0.00750 & 0.996 \\
\hline
\end{tabular}

\section{Influence of curing time on impact energy absorption characteristics}

For artificially cemented sand specimens, sand particles are bonded by cement particles and gypsum particles [7, 22]. The contact mechanical characteristics between sand particles are directly determined by the hydration process of cement particles and gypsum particles [23, 24$]$. For cement particles, the hydration process continues with curing time increasing, thus the contact mechanical characteristics between sand particles increase gradually [7, 25]. Under impact load, absorbed energy of artificially cemented sand is consumed to break the bonding connections between sand particles and separate sand particles.

Under certain striker velocity, impact energy absorption characteristics of artificially cemented sand are different for various curing times. The relation between average specific energy absorption of artificially cemented sand and curing time under different striker velocities are shown in Fig. 6.

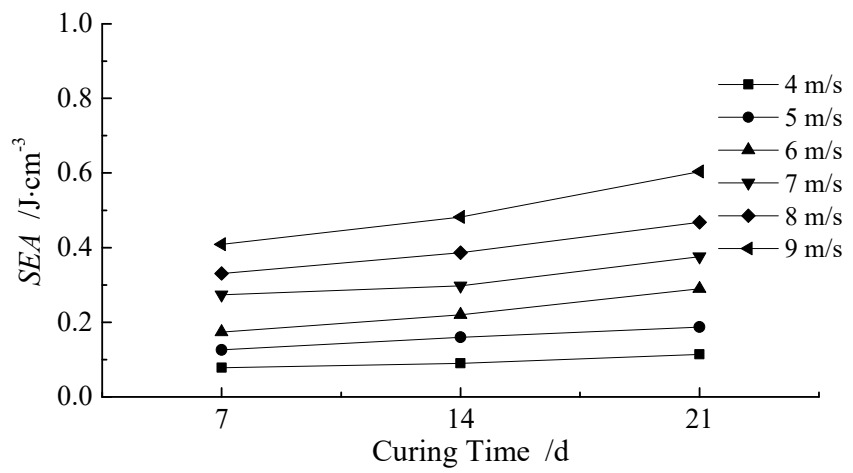

Fig. 6. Curve of specific energy absorption versus curing time for artificially cemented sand

Seen from Fig. 6, average specific energy absorption of artificially cemented sand gradually increases with curing time increasing under certain striker velocity. And the increasing rate from 7 days to 14 days is slower, while it is faster from 14 days to 21 days.

To compare the impact energy absorption characteristics of artificially cemented sand in different curing times quantitatively, impact energy absorption increase factor (IEAIF) is put forward and defined as the ratio of specific energy absorption of artificially cemented sand cured 14 days or 21 days to that cured 7 days: 
$I E A I F=\frac{S E A}{S E A_{7}}$

where $S E A_{7}$ is specific energy absorption of artificially cemented sand cured 7 days.

The relation between impact energy absorption increase factor (IEAIF) and striker velocity $(v)$ for artificially cemented sand cured 14 days and 21 days are shown in Fig. 7.

Seen from Fig. 7, impact energy absorption increase factor (IEAIF) of artificially cemented sand cured 14 days is in the range of 1.09 to 1.27 under various striker velocities, and its mean value is 1.19 . While impact energy absorption increase factor (IEAIF) of artificially cemented sand cured 21 days is in the range of 1.37 to 1.67 under various striker velocities, and its mean value is 1.48 . There is an obvious oscillation phenomenon when impact energy absorption increase factor changes with striker velocity increasing, which may be affected by the discreteness during impact uniaxial compression tests.



Fig. 7. Curve of impact energy absorption increase factor versus striker velocity for artificially cemented sand

The authors declare no conflict of interest.

\section{Conclusions}

With the help of aluminum split Hopkinson pressure bar apparatus with diameter of $37 \mathrm{~mm}$, impact uniaxial compression tests for artificially cemented sand cured 7 days, 14 days, and 21 days are carried out under various striker velocities. Then specific energy absorption (SEA) of artificially cemented sand specimens are analyzed, and the influence of curing time on impact energy characteristics are also studied. For relatively low wave impedance of artificially cemented sand, most of incident wave in impact uniaxial compression tests is reflected, thus transmitted energy is relatively small. With striker velocity increasing, specific energy absorption (SEA) of artificially cemented sand in various curing times increases in a positive linear function with squared striker velocity. Under certain striker velocity, impact energy absorption characteristics of artificially cemented sand increase gradually with curing time increasing. And the increasing rate from 7 days to 14 days is slower, while it is faster from 14 days to 21 days. Average impact energy absorption increase factor (IEAIF) of artificially cemented sand cured 14 days and 21 days are 1.19 and 1.48, respectively. And there is an obvious oscillation phenomenon when impact energy absorption increase factor (IEAIF) changes with striker velocity increasing.

\section{Acknowledgements}

This research was funded by National Natural Science Foundation of China (No. 51174004, No. 51374012), Science and Technology Project of Department of Housing and Urban-Rural Development of Anhui Province (No. 2017YF-08). This research was also funded by Young 
Teacher Scientific Research Project of Anhui University of Science and Technology (No. QN201607).

\section{References}

[1] Chen A. M., Gu J. C., Shen J., Ming Z. Q., Gu L. Y., Lu Z. Y. Application study on the geomechanical model experiment techniques. Chinese Journal of Rock Mechanics and Engineering, Vol. 23, Issue 22, 2004, p. 3785-3789.

[2] Yuan P., Xu Y., Xue J. H. Model test of anchorage deep tunnel in blasting excavation. Chinese Journal of Rock Mechanics and Engineering, Vol. 35, Issue 9, 2016, p. 1830-1836.

[3] Yang R. S., Zhang Y. F., Yang L. Y., Wu Y. L., Ma J. H. Study on the mixing proportion test of similar material gypsum. China Mining Magazine, Vol. 22, Issue 10, 2013, p. 125-130.

[4] Yuan P., Xu Y., Zheng Z. T. Time-frequency analyses of blasting vibration signals in single-hole blasting model experiments. Journal of Vibroengineering, Vol. 19, Issue 1, 2017, p. 363-375.

[5] Zhang X. T., Zhang Q. Y., Cao G. H., Xu X. B. Effects on iron-barite-sand mixed similar material properties induced by molding pressure. Journal of Shandong University (Engineering Science), Vol. 43, Issue 2, 2013, p. 89-95.

[6] Consoli N. C., Cruz R. C., Floss M. F. Variable controlling strength of artificially cemented sand: influence of curing time. Journal of Materials in Civil Engineering, Vol. 23, Issue 5, 2011, p. 692-696.

[7] Yuan P., Xu Y. Influence of curing time to compressive properties of cemented sand similar materials. Journal of Vibration and Shock, Vol. 34, Issue 13, 2015, p. 200-204.

[8] Xie H. P., Peng R. D., Ju Y., Zhou H. W. On energy analysis of rock failure. Chinese Journal of Rock Mechanics and Engineering, Vol. 24, Issue 15, 2005, p. 2603-2608.

[9] Zhang Z. Z., Gao F. Research on nonlinear characteristics of rock energy evolution under uniaxial compression. Chinese Journal of Rock Mechanics and Engineering, Vol. 31, Issue 6, 2012, p. 1198-1207.

[10] Cai M. F., Ji D., Guo Q. F. Study of rockburst prediction based on in-situ stress measurement and theory of energy accumulation caused by mining disturbance. Chinese Journal of Rock Mechanics and Engineering, Vol. 32, Issue 10, 2013, p. 1973-1980.

[11] Wang Y. H., Chen L. W., Shen F. Numerical modeling of energy release in rockburst. Rock and Soil Mechanics, Vol. 29, Issue 3, 2008, p. 790-794.

[12] Chen X. G., Zhang Q. Y. Mechanism analysis of phenomenon of zonal disintegration in deep tunnel model test under high geostress. Rock and Soil Mechanics, Vol. 32, Issue 1, 2011, p. 84-90.

[13] Yuan P., Xu Y. Dynamic compressive characteristics of cemented sand similar material in uniaxial state and passive confining state. Electronic Journal of Geotechnical Engineering, Vol. 20, Issue 23, 2015, p. 11717-11728.

[14] Pankow M., Attard C., Waas A. M. Specimen size and shape effect in split Hopkinson pressure bar testing. The Journal of Strain analysis for Engineering Design, Vol. 44, Issue 8, 2009, p. 689-698.

[15] Yuan P., Ma Q. Y., Zhang H. D. SHPB tests for light weight foam concrete. Journal of Vibration and Shock, Vol. 33, Issue 17, 2014, p. 116-119.

[16] Ma Q. Y. Experimental analysis of dynamic mechanical properties for artificially frozen clay by the split Hopkinson pressure bar. Journal of Applied Mechanics and Technical Physics, Vol. 51, Issue 3, 2010, p. 448-452.

[17] Miao Y. G., Li Y. L., Deng Q., Tang Z. B., Hu H. T., Suo T. Investigation on experimental method of low-impedance materials using modified Hopkinson pressure bar. Journal of Beijing Institute of Technology, Vol. 24, Issue 2, 2015, p. 269-276.

[18] Song B., Chen W. Energy for specimen deformation in a split Hopkinson pressure bar experiment. Experimental Mechanics, Vol. 46, Issue 3, 2006, p. 407-410.

[19] Yuan P., Ma R. Q. Analysis of energy absorption of rock under various water absorption conditions in SHPB test. Acta Armamentarii, Vol. 34, Issue 1, 2013, p. 328-332.

[20] Yuan P., Ma Q. Y. Energy analyses of uniaxial impact compressive tests for coalmine sandstone after cyclic wetting and drying. Rock Engineering and Rock Mechanics: Structure in and on Rock Masses, Proceedings of Eurock, Taylor and Francis, Balkema, 2014, p. 101-105.

[21] Su H. Y., Xu J. Y., Bai E. L., Luo X., Xi Y. Y. Experimental study on anti-impact performance of ceramic fiber reinforced concrete. Journal of Building Materials, Vol. 16, Issue 2, 2013, p. 237-243.

[22] Wang Y. H., Leung S. C. A particle-scale investigation of cemented sand behavior. Journal of Geotechnical and Geoenvironmental Engineering, Vol. 45, Issue 1, 2008, p. 29-44. 
[23] Jiang M. J., Jin S. L., Liu W., Liu J. Three-dimensional experimental study of mechanical behaviors of bonded materials. Rock and Soil Mechanics, Vol. 36, Issue 1, 2015, p. 9-13.

[24] Wang L. G., Xi Y. H., Liu X. F., Chen Q., Zhang Y., Pan J. W. Physical and mechanical properties of cemented body of sand grains with different diameter. Bulletin of the Chinese Ceramic Society, Vol. 35, Issue 1, 2016, p. 61-67.

[25] Liu P., Yu Z. W., Chen L. K. Influence of curing age on properties and micro structure of concrete. Journal of Building Materials, Vol. 15, Issue 5, 2012, p. 717-723.

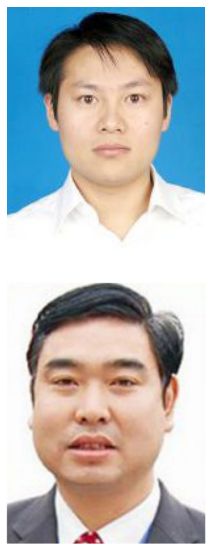

Pu Yuan received Ph.D. degree in civil engineering from Anhui University of Science and Technology, Huainan, P. R. China, in 2016. Now he works at Anhui University of Science and Technology. His current research interests include monitor and control of blasting vibration and dynamic mechanical properties of engineering materials.

Ying $\mathrm{Xu}$ received Ph.D. degree in engineering mechanics from University of Science and Technology of China, Hefei, P. R. China, in 2003. Now he works at Anhui University of Science and Technology. His current research interests include monitor and control of blasting vibration, control blasting technology and rapid excavation of deep roadway in coal mine. 